\title{
Samech.
}

Von A. Müller.

Herr Geheimer Rath de Lagar de sagt am Anfange der eingehenden und vielseitigen Untersuchung, welche er soeben dem Samech gewidmet hat, auf S. 165 des laufenden Jahrgangs der Göttinger Nachrichten : „Ueber $\square$ reden Ewald ... F Böttcher ... hin und her. J Olshausen schweigt."

Dies ist nicht richtig. Olshausen sagt $\S 6$ e (S. 10) seines Lehrbuches der hebräischen Sprache : „Die Zahnlaute zeigen ebenfalls eine regelmälsige Abstufung zwischen einem scharfen $\mathrm{s}^{1}$ ) und einem gelinden (französischen) $\mathrm{z}$, zu welchen ein abnorm gebildeter Laut tritt, der mit ç bezeichnet werden mag und der Reihe $\varepsilon q t$ entspricht. Eine gröfsere Erweichung ist aber hier so wenig möglich, wie bei den Zungenlauten, mit welchen die Zahnlaute noch am nächsten verwandt sind. Dagegen findet sich neben dem scharfen s noch ein anderer Zischlaut, welcher nach der besten Ueberlieferung dem deutschen sch nahe steht, ohne dessen Stärke zu erreichen, und hier mit $\mathrm{s}^{2}$ ) bezeichnet werden mag. Von dem Laute des scharfen $s$ hat sich frühzeitig, obwohl lange nach Einführung der hebräischen Consonantschrift, ein gequetschter Zischlaut, ś, dem deutschen sch entsprechend, abgezweigt."

Ich bin immer der Absicht gewesen, dafs der sel. Olshausen nicht nur ein sehr gelehrter und höchst vorsichtiger, sondern auch ein sehr kluger Mann war, und habe mich nach Kräften gewöhnt, jede Zeile, die er geschrieben hat, sorgfältig zu betrachten, weil ich weifs, dafs hinter seinen unscheinbarsten Wendungen stets eine Fülle genauer

1) Damit meint Olshausen das hebräische $\boldsymbol{E}$.

2) So umschreibt Olshausen das $D$. 
und umsichtiger Erwägungen liegt. Ich habe deswegen auch nie versäumt, seine Auffassung der „Zahnlaute ${ }^{*}$ in meinen Vorlesungen über die hebräische Grammatik zu erwähnen, ohne indes bei der Beschränktheit meiner Kenntnisse auf diesem Gebiete die Ueberlegungen. welche in diesem Falle ihn zu seinen von dem Gewöhnlichen so weit abweichenden Aufstellungen vermocht hatten, mir vollständig klar machen zu können. Ich bin - und andere werden es mit mir sein - Herrn Geheimrath de Lagarde dankbar, dals seine Ausführungen, mit welchen ich mich hier nicht weiter beschäftigen darf, mir abgesehen von sonstiger Belehrung auch zum gröfsten Theil das Verständnifs für Olshausens Sätze eröffnet haben, und ich glaubte diesen Dank nicht besser abstatten zu können, als wenn ich die von ihm übersehene Stelle aus dem seines anscheinenden Schematismus wegen vielfach nicht mehr wie früher gewürdigten Buche Olshausens hier nachtrüge.

Halle, 8. August 1891.

\section{Raschi's Einflufs auf Nikolaus von Lyra in der Auslegung des Exodus.}

Ein Beitrag zur Geschichte der Exegese des alten Testamentes.

Von Felix Maschkowski, cand. phil.

Herr Prof. Siegfried betont in seiner Rede : „die Aufgabe der Geschichte der Alttestamentlichen Auslegung in der Gegenwart" (Jena 1876) den grofsen Einflufs, welchen die jüdische Schriftauslegung auf die christliche Exegese zur Zeit der Kirchenväter und des Mittelalters ausübte, und weist darauf hin, dafs aus Mangel an hierauf bezüglichen Vorarbeiten eine zusammenfassende Darstellung der 